\title{
Rhematization as Etiology in the Diagnosis of Posttraumatic Stress Disorder
}

\section{Cover Page Footnote}

This paper was only possible through the generous feedback and reference suggestions by Kira Hall, Kathryn Goldfarb, and Chase Raymond. 


\title{
RHEMATIZATION AS ETIOLOGY IN THE DIAGNOSIS OF POSTTRAUMATIC STRESS DISORDER
}

\author{
AYDEN PARISH \\ University of Colorado Boulder
}

\begin{abstract}
Current psychiatric nosology emphasizes observable symptoms as the central schema by which mental illnesses should be classified; patients are identified as depressed or schizophrenic by virtue of observed behavior or reported experiences, rather than theoretical underlying causes that may lead to an array of diverse presentations. Within this schema, the diagnosis of posttraumatic stress disorder (PTSD) is somewhat an outlier - its identification relies not only on overt symptomatology, but also the identification of a particular etiology from traumatic moment to current distress. That is, symptoms diagnosed as PTSD not only index that diagnostic category, but also a previous pathogenic trauma. This indexicality is bolstered by an act of rhematization, the transformation of indexical relationships into iconic links, whereby PTSD symptoms are understood as resembling a pathogenic trauma, thus distinguishing PTSD from disorders whose presentations carry no such resemblance to trauma.
\end{abstract}

Keywords: indexicality, rhematization, posttraumatic stress disorder, trauma

\section{INTRODUCTION AND HISTORY}

Diagnosis is an act of semiosis, transforming abnormal test results and distressing experiences into meaningful signs that point to a specific disease entity. The meaning created by the diagnostician's interpretation is indexical: As signs, symptoms point to their diagnoses by virtue of being causally linked to them, a conclusion that has been readily drawn by semioticians (Eco 1976; Ostwald 1964; Peirce 1931-1958; Sebeok 1994). As a psychiatric disorder uniquely defined by its traumatic cause, posttraumatic stress disorder (PTSD) carries a particularly heavy reliance on indexical and ultimately rhematized links in order to justify itself as a discrete diagnostic entity.

In most areas of medicine, conditions are categorized first and foremost on their causes. Viral and bacterial bronchitis both cause an unpleasant cough, yet they are distinguished by different pathogens, ultimately leading to different treatment plans. However, psychiatry ultimately rests its categorization schema on groups of observable symptoms. This aspect of modern psychiatry can be traced back to early $20^{\text {th }}$ century psychologist Emil Kraepelin and is therefore considered the NeO-Kraepelinian approach (Blashfield 2012; Compton \& Guze 1995). Under a neo-Kraepelinian model, everyone who experiences similar feelings of lethargy, anhedonia, and excessive guilt are prima facie classed together under depressive. This stands in contrast with earlier largely 
psychodynamic approaches that prioritized theoretical underlying causal mechanisms as the basis of categorical generalizations, such that a single cause like weak ego defenses may lead to a range of different presentations while still being theorized as a single entity. While Kraepelin imagined that shared causal mechanisms would eventually be identified across shared presentations of symptoms once thusly categorized, for the most part this has yet to happen.

The Diagnostic and Statistical Manual of Mental Disorders (DSM), published by the American Psychological Association (APA), is for many the ultimate authority of what counts as a mental illness in the United States (and is an influence in many other places of the world). ${ }^{1}$ It was the third edition of this manual, released in 1980, that truly solidified the neo-Kraepelinian approach in what several authors have described as nothing less than a "revolution" (Compton \& Guze 1995; Mayes \& Horwitz 2005; Wilson 1993). By emphasizing ostensibly neutral descriptive categories over psychoanalytic etiologies, which could differ between professionals, the psychologists who wrote the DSM-III hoped to bring a kind of "scientific objectivity" to the field. The DSM-III asserted itself as an "atheoretical" text whereby "clinicians can agree on the identification of mental disorders on the basis of their clinical manifestations without agreeing on how the disturbances come about" (APA 1980:7). The exception, highlighted in the introduction, was for disorders for which "the etiology or pathophysiological processes are known" (6), such as the organic mental disorders diagnosed after identification of a specific neurological abnormality.

The DSM-III was also noteworthy for introducing a range of new terminologies and diagnostic categories, not simply reorganizing and redefining preexisting ones. One of these was posttraumatic stress disorder (PTSD), a diagnosis whose inclusion largely came from political pressure by war veterans (Scott 1990). Advocates argued that doctors could only properly treat these veterans if they formally recognized the etiological impact of trauma, and that the "misdiagnosis" of veterans with disorders such as bipolar and schizophrenia was a grave injustice. Consequently, at the same time as wide swathes of the DSM were written to avoid suggesting specific causes in the name of being "atheoretical," we also see the creation of a disorder specifically defined by its theoretical causes.

\footnotetext{
${ }^{1}$ Outside of the United States, the World Health Organization's (WHO) International Statistical Classification of Diseases and Related Health Problems (ICD) acts as the authoritative text on psychiatric nosology. However, there have been efforts by both WHO and APA to reconcile the two systems.
} 
Through the lens of indexicality (Silverstein 1976) and rhematization (Irvine and Gal 2000), I suggest that for PTSD to claim legitimacy within a psychiatric framework purporting pure descriptivism, causes must be made just as observable as depressed or anxious affects. This may be done by reading symptoms as unproblematic indexes not just of diagnostic category, the way hallucinations may index schizophrenia, but as rhemes that both point to and phenomenologically resemble a specific trauma. Without an etiological cause, a "purely descriptive" rendering of PTSD overlaps considerably with other diagnostic categories: The avoidance of triggering material, mood instability, and even flashbacks may be described as phobic, mood disordered, and psychotic respectively (Brewin et al. 2009; McHugh \& Treisman 2007; Young 1995). It is the ability to read a particular causal chain from them that transforms these into symptoms of PTSD.

\section{INDEXES, RHEMES, AND CAUSES}

INDEXICALITY describes a sign, linguistic or otherwise, that relies on contextual information in order to be interpretable. The current wide use of indexicality can be traced back to Charles Perice's tripartite system of types of signs, split by their relation to their signified Object: icons, indexes, and symbols. ICONS are signs whose relation to their signified is one of resemblance or shared qualities, as when a drawn stick figure signifies a human being. symbols are signs whose meanings are purely a matter of convention and which are otherwise wholly arbitrary, such as how the sounds in the word $d o g$ mean a particular class of mammal. The relation that defines an INDEX is an existential one: An index "refer[s] to the Object that it denotes by virtue of being really affected by that Object" (Peirce 1931-1958:CP 5.248). This may include physical or spatial contiguity, which directs the interpreter's attention towards the signified Object—such as when a pointed index finger directs attention towards a particular location in space—or, potentially, causal links. An important aspect of this definition is that the interpretation of indexical signs requires an assumption that there is something that exists external to the utterance. Smoke indexes fire not because of an arbitrary symbolic relationship, but because the chain of causation from smoke to fire proceeds (in theory) regardless of semiotic interpretation. This connection to a world beyond the sign results in a reliance on contextual information.

Indexicality has then been taken up as a way to talk about context-dependent meanings, exemplified in deictic expressions such as here, now, $I$, and you. Without sufficient information about the context of the utterance-namely, when it was uttered-the word now holds little 
meaning. However, cONTEXT is a commonly used word without a clear, uniform definition. Common uses highlight its co-constitutive importance to техт: Context is not the "focal point" or "figure," but rather the "everything else" that allows for successful interpretation (Goodwin \& Duranti 1992). While this may result in a slightly circular definition-indexicality is that which requires external context, while context is that which is required by indexicality - there is an important insight here: Due to the endless possibility of language, everything can be recruited as potential context. Think of all the locations that here could possibly refer to! It is the indexical reference itself that transforms inert facts about the world into salient, necessary, contextual information - into socially relevant Objects that can be discussed and reasoned about.

Attention to indexicality helped move the study of meaning away from pure referential semantics, which takes up the study of relatively context-free sentences such as the sky is blue, towards a study of language that necessitates acknowledging its embeddedness in a particular, and a particularly social, context. It is for this reason that indexicality came to be most strongly associated with disciplines that joined language and social reality. Silverstein (1976) is credited with bringing the concept of indexicality to linguistic anthropology. He described two actions that an indexical utterance can accomplish: PRESUPPOSING and PERFORMING. Because they presuppose some particular context, the indexical deictic terms this and that are uninterpretable and nonsensical if the relevant context is not known; the presupposition fails and meaning breaks down. Performative indexicality, also called creative or entailing indexicality, likewise relies on contextual information, but also "seem[s] to be the very medium through which the relevant aspect of the context is made to "exist"' (Silverstein 1976:34). Objects which can be referred to as this or that generally in some way precede their entrance into discourse; however, indexes such as honorifics, which nevertheless require the preexisting context of social convention and a power dynamic among speakers, also enact these social relations in being uttered. When these sorts of indexes "fail," rather than being referentially baffling, they often change the nature of their medium: Honorifics spoken in the wrong contexts may be taken as an insult — a very different kind of social action than the same forms spoken in a different context. These latter indexes fit Austin's (1962) understanding of performativity: They construct their context while simultaneously reflecting it.

Rather than constituting two separate classes of indexicality, presupposed and creative indexicality exist along a range of possibilities. Many indexical utterances can be found to both 
presuppose and perform. Silverstein gives the example of first-person pronouns: Like other deictics, they presuppose the existence of a person or persons who precede entrance into the discourse-without this context, they are incomputable. However, as first-person pronouns generally mean something like "the speaker of this utterance," they also create the necessary discourse environment and the notion of a speaking $I$ at all. Along the same lines, the word we just as much refers to a preexisting collection of people as it constructs or reinforces a shared group identity.

Silverstein's ideas were further refined through the proposal of an INDEXICAL ORDER to explain how indexical relations are formed and manipulated in the moment (Silverstein 2003). This ordering begins with first-order indexicality: the utterance specific non-referential meanings that come from using one linguistic variant over another. Second-order indexicality refers to how this variation is expanded into ideological, metapragmatic meanings as communities attempt to rationalize why linguistic variation exists. A linguistic feature that is recognized by speakers as associated with a certain demographic or location (first-order) can come to signify a certain "type of person" under a particular language ideology (second-order). The word y'all may be statistically more common in the southern United States; however, the social identities attributed to the word, such as "rural," are second-order indexical meanings that can then be drawn upon when anybody, not just those in the American South, say y'all.

This ordering turns on itself indefinitely as speakers draw from second-order indexical meanings, changing the speaker demographics of the linguistic form and generating new metapragmatic understandings: "for any indexical phenomenon at order $n$, an indexical phenomenon at order $n+1$ is always immanent, lurking in the potential of an ethnometapragmatically driven native interpretation" (Silverstein 2003:212). Silverstein's class example deals with the highly marked register of wine connoisseurship. This style draws heavily from ideologies regarding what "well-bread," "expert," and "high-class" persons sound like. By "wine-talking," speakers index themselves as wine experts - a type of person that is ideologically linked to above-average intelligence, specialized knowledge, and high socioeconomic class. But what determines what "high-class" persons sound like? It is a second-order understanding of the language varieties found among certain populations, namely the white, rich, and educated. As always, however, $n+1$ st order indexicality is possible: Self-conscious, ironic uses of wine-talk create a new kind of person, namely the kind of person who uses wine-talk ironically. Indexical 
ordering then functions as a dialectic, a back-and-forth shifting of language use and language ideology that changes just as soon as speakers develop a metapragmatic understanding of their language variation. For this reason, the terms $n$th order and $n+1$ st order are preferred to first- and second-order indexicality - there is no easy way of assessing which (if any) aspects of speaker variation truly came first, absent of any ideological baggage.

Peirce identified causality as a potential source of indexical relations, specifically calling these causality-based indexical signs REAGENTS. An early example of this was the weathercock, whose position is dictated by the direction of the wind and which therefore indexes this causal force (Peirce 1931-1958:CP 2.286). Indexicality, by pointing towards pre-existing reality, situates itself in a material world of objects acting upon other objects; this attention to materiality has been described by Keane (2003) as a way to "open up signification to causality" (417). However, while Peirce seemed to imagine these relations as belonging to the world "irrespective of the Interpretant" (CP 2.92), Keane noted that there must be ideologies in play that make certain connections recognizable at all. He named these sEMIOTIC IDEOLOGIEs: "basic assumptions about what signs are and how they function in the world" (419).

These ideologies seem obvious and natural to its holders, and when asked, people can usually give some form of internally-logical explanation for their beliefs. It should be natural, for example, that men should swear more: It's because of testosterone, innate aggressiveness, socialized competitiveness, and so on. Swearing therefore not only indexes masculinity by virtue of convention or mere metapragmatic recognition-i.e., "that's just the way men speak" without any further value judgements - but seems to on some level resemble or reflect masculinity's supposed innate aggression and violence. Irvine and Gal (2000) would describe this as an instance of ICONIZATION, later renamed RHEMATIZATION. ${ }^{2}$ Discussing the rhematization of certain linguistic forms as both indexing and resembling (that is, iconifying) their ideological referents, they described a transformation of the sign relationship between linguistic features (or varieties) and the social images with which they are linked. Linguistic features that index social groups or

${ }^{2}$ Gal's (2005) recasting of this process as RHEMATIZATION draws from Peirce's (1940) definition of a RHEME as “a Sign which, for its interpretant, is a Sign of qualitative possibility, that is, is understood as representing such and such a kind of possible Object" (103) - in other words, a sign that is interpreted to have qualities (QUALIA) which are shared with and thus represent some object. 
activities appear to be iconic representations of them, as if a linguistic feature somehow depicted or displayed a social group's inherent nature or essence (37).

That is, the merely indexical relationship between a speech variety and a social identity may be rendered as somehow iconic, such that qualities of language are seen to resemble qualities ascribed to said social group.

\section{IDENTIFYING TRAUMA}

The diagnosis of PTSD recontextualizes past events into instances of trauma and present cognition or emotions into symptoms of PTSD. It is a potentially paradigm-shifting heuristic through which sufferers and helpers can reinterpret the past and present, imbuing a person's actions and feelings with a newfound ability to index a traumatic event. That is, there is a sense in which the presently constructed narrative of PTSD grants past events the ability to cause. Cause and effect blur further when it is the presence of symptoms that lead clinicians to posit a diagnosis of PTSD even in the absence of clearly-identified traumatic memories (e.g. Bass \& Davis 1988; Laibow \& Laue 1993). Young (1996:97-98) goes as far as suggesting that

chronic cases of PTSD can be explained just as plausibly if we supposed that time is moving in the opposite direction, that is, from the present (symptoms) back to the past (event). In this scenario, diagnosable depression and anxiety disorders precede the onset of PTSD symptomatology (rather than following or simply co-occurring), and individuals rediscover and rework their memories of past events as a means of accounting for their present distress.

This is a troubling scenario, if the nature of indexical links relies on time flowing from cause to event. If indexes are meant to point towards their causes, then this is a form of INDEXICAL INVERSION, a term used by Inoue (2004) to describe how the ethno-metapragmatic explanations that define $n+1$ st order indexical might point to a history — specifically, a linguistic history — that never truly existed. She examined how the idea of women's language in Japan was formed again and again in order to lament its destruction: "the birth of women's language was also the birth of the corruption of women's language" (50). It did not necessarily exist even as a statistical correlation until the metapragmatic discussions about the denigrations of women's language presupposed it into existence. The "corruption" of women's speech in the late 19th and early 20th was ascribed varyingly to low-class neighborhoods in Tokyo, geisha, the mixing of social classes 
in high schools, and contact with Westerners. Regardless of proposed origin, the ultimate meanings of this corruption were widely agreed upon: sloppiness, laziness, and vulgarity.

By suggesting a degree of indexical inversion, I do not mean to suggest that the memories and their effects are invented wholesale; however, their structuring and scaffolding under the framework of trauma relies on the naming of current symptoms as posttraumatic and on the historically and culturally specific science of trauma - in other words, the present-day ideologies that dictate what is defined as trauma. The historically situated nature of these recastings is perhaps clearest in the case of child abuse, which has undergone numerous shifts in meaning over the past century (Hacking 1991). Events which at the time were not considered abusive or traumatic-were not Objects that could be easily indexed by symptoms - become in hindsight instances of child abuse and neglect.

An anxiety surrounding the diagnosis of PTSD, then, is ensuring that this powerful indexicality is granted fairly - that there exists a true Object being indexed and that the causality supporting the indexical relation is an accurate narrative. Causation, after all, evokes blame: The identification of a particular event as causing PTSD opens up the possibility of legal recourse on the basis of psychological injury (Day \& Hall 2016; Miller 2015). Military veterans who can trace their symptoms to PTSD from a wartime trauma can access disability benefits and resources more easily than if their distress was due to an ostensibly non-traumagenic disorder such as schizophrenia (Ray 2014).

A seemingly straightforward tactic for determining an adequate causal chain is to ensure that the problematic symptoms only arose after the traumatic event in question. However, even this may prove difficult: PTSD is an appropriate diagnosis if trauma only exacerbates preexisting psychiatric symptoms, and there exists the classification of delayed-onset PTSD when symptoms arise months or years after the traumatic event. Additionally, while temporal ordering can suggest causality, it is rarely sufficient as a convincing narrative-indeed, a series of events one after another may be better thought of as "chronicles" than "full-fledged narratives" (Carroll 2001:25). PTSD by its nature requires more than a mere chronicle of events; psychiatrists need stronger causal links.

Young (1995) provided multiple cases of doctors debating the truth of their veteran patients' etiologies. If there were potential traumatic events prior to the wartime events in Vietnam, then there existed a promising alternative narrative wherein the patient's PTSD was only caused by 
these earlier events; therefore, it was not the obligation of the military hospital to provide treatment. These doctors also struggled with articulating the clear moral evaluation that would point towards a stronger narrative: Trauma related to atrocities that the soldier was himself responsible for or personally carried out-so-called perpetrator trauma-complicated any depiction of the veteran as a blameless victim of circumstance and casted suspicion on claims of PTSD. This debate has resurfaced in more recent years centered on cases of PTSD claimed by American drone operators, who are not only viewed as perpetrators but also have to reckon with the difficulties of proving causation across such large distances (McCammon 2017; Press 2018; for further discussions on the continuing controversy over perpetration as a source of traumatic stress, see Drescher et al. 2011).

A common struggle was - and continues to be (Breslau et al. 2002) - the identification of as specific a traumatic moment as possible. It was not sufficient to suggest that war in general was traumatic, even when veterans themselves suggested this more diffuse understanding of causality; doctors sought out information about particular battles and even homed in on what event with in a battle constituted "the trauma." Indeed, the idea of a posttraumatic disorder caused by multiple different events over a span of time, as might happen within dysfunctional family dynamics, has been proposed through the alternative construct of "complex posttraumatic stress disorder." After some debate, complex PTSD was ultimately omitted from the most recent edition of the DSM, with skeptics highlighting how research had yet to clearly illustrate the casual mechanisms from chronic traumatization to the wide range of symptoms described by the proposed disorder, which furthermore overlapped considerably with other diagnoses (Resick et al. 2012; Şar 2011). In other words, complex PTSD lacked a good, clear causality.

\section{RHEMATIZING TRAUMA}

To help determine what event to highlight and ultimately treat as the pathogenic trauma, doctors and patients turn not only towards the presence or absence of certain symptoms, but also their content. Symptoms such as nightmares, flashbacks, and anxiety should all point to the same event, otherwise a diagnosis of PTSD would seem inappropriate (Breslau et al. 2002). Certain symptoms of posttraumatic stress disorder are seen as not only pointing to the etiological event, but furthermore somehow resembling it. FLASHBACKS are "a dissociative state during which aspects of a traumatic event are reexperienced as though they were occurring at that moment" (APA 
2013:821). The images and sensations of a flashback are similar to - if not indistinguishable from - those same images and sensations experienced during the causal trauma.

In much of the popular trauma literature, flashbacks are viewed as a privileged form of remembering (Antze 1996; Hacking 1995) and perhaps even unique to posttraumatic disorders (Brewin et al. 2009). Under this ideology, nontraumatic memories are prone to distortion through narrativization, reconstruction, and revision; traumatic memories, on the other hand, and particularly those experienced through disorienting flashbacks, are in some way frozen in time. In van der Kolk's (2013) best-selling book about trauma, The Body Keeps the Score, he writes

Stories change and are constantly revised and updated ... Such autobiographical memories are not precise reflections of reality; they are stories we tell to convey our personal take on our experiences (177).

In contrast,

The imprints of traumatic experiences are organized not as coherent logical narratives but in fragmented sensory and emotional traces: images, sounds, and physical sensations (178).

Isolated from narrative, such "imprints" can then "be re-experienced without appreciable transformation months, years, or even decades after the actual event occurred" (van der Kolk 2002:57, emphasis added). Narrative memories can index, in the sense that they point to previous events; traumatic memories iconify, and just as the rhematization of certain linguistic features reifies the "naturalness" of their associations with specific social identities, rhematization makes natural and self-evident the causal links between trauma and symptomology.

What allows for this rhematization? Hacking (1995), in his analysis of the similarly posttraumatic condition of dissociative identity disorder, coined the term MEMORO-POLITICS to refer to the disciplining of memory into an object of knowledge. Paralleling Foucault's (1978) BIOPOLITICS and ANATOMO-POLITICS, memoro-politics involves the control over the right and wrong was to have memories, structure one's biography, and tell stories about oneself. These amount to what Hacking called "the sciences of the soul," taking soul to involve "character, reflexive choice, and self-understanding, among much else" (215) and what I may reconfigure as respectively morality, agency, and the reflexive presentation of self, situated within an ideology of what memory is and how it functions. The changing sciences of child abuse have changed what it means to have a childhood: Not only can one rename past events as trauma, but the possibility of repressed 
memories creates new narrative arcs and identities (such as the survivor with repressed memories) and the language of flashbacks provides a new form of evidence to support the causal link between traumatic event and symptoms - a particular form of indexical iconicity.

It is helpful here to consider other instances of perceiving images or sensations that others do not perceive: hallucinations, particularly those associated with psychosis. Before posttraumatic stress disorder was an available diagnosis, many veterans were labelled schizophrenic partially on the basis of hallucinatory experiences, which at times may even include the prototypically psychotic auditory verbal hallucinations (Crompton et al. 2017; McCarthy-Jones \& Longden 2015; Scott 1990; Young 1995). The DSM-5 outlines the need to differentiate between hallucinations and flashbacks, advising that "flashbacks are distinguished from these other perceptual disturbances [hallucinations] by being directly related to the traumatic experience and by occurring in the absence of other psychotic or substance-induced features" (APA 2013:286). This direct relation seems to mean an iconic one, as studies have found individuals diagnosed with schizophrenia whose hallucinatory experiences share only "thematic" or "indirect" relations to trauma (Hardy et al. 2005; McCarthy-Jones \& Longden 2015; Morrison et al. 2003). Without content that can be understood as iconic of a pathogenic trauma, psychotic hallucinations are not understood as flashbacks and will likely not be viewed as caused by trauma at all.

\section{CONCLUSION: CURING CAUSALITY}

All diagnosis is a matter of giving meaning to symptoms reported by or observed in a patient. This interpretation is largely indexical in nature, as symptoms point towards their causes. Posttraumatic stress disorder holds a particularly noteworthy tie to indexicality due to its uneasy status under the neo-Kraepelinian philosophy of modern psychiatry, which privileges empirical observations over theorized causes. Unlike a disorder like schizophrenia, which relies on the identification of present-day symptoms as kinds of hallucinations or delusions, PTSD requires the articulation of a certain type of background - a pathogenic trauma — before symptoms can be read as properly connected to PTSD. Therefore, if symptoms can be made to index a pathogenic trauma with the same self-evidence that anxiety can index an anxiety disorder, then posttraumatic disorder remains a coherent category. On the other hand, that fact that PTSD symptoms overlap with those of other disorders has led some scholars to question whether there is anything truly unique about traumatic events and whether arguably nontraumatic events could lead to the same presentation, 
which would potentially undermine the very existence of PTSD and a distinct diagnosis and trauma as a concept (Bodkin et al. 2007; Brewin et al. 2009; McNally 2003). In defense of causality, doctors and patients draw from rhematized relationships between symptoms and a patient's past.

Finally, PTSD's strong ties to rhematization can be found in its treatment. One dominant treatment philosophy lies in the proposed difference between traumatic and nontraumatic memory as fragmented iconicity and properly ordered narrative respectively. Treatment methodologies such as Eye-Movement Desensitization and Repressing (EMDR), a form of psychotherapy recommended by the U.S. Department of Veterans Affairs and the American Psychiatry Association, exist to help the patient integrate traumatic memories into their life story, so that "the memory is transformed into a symbolic verbal account ... an autobiographical narrative memory of traumatizing events" that no longer phenomenologically resembles the original traumas (van der Hart et al. 2006:319; see also Fisher 2014; Shapiro 2001; van der Kolk 2013). Once the processing of remembering is made less iconic, the strict, pathological causal links from past to present slowly unravel. Symptoms abate or become more manageable until the patient's day-today life finally no longer carries rhemes of trauma.

\section{REFERENCES}

Antze, Paul. 1996. Telling stories, making selves: Memory and identity in multiple personality disorder. Tense past: Cultural essays in trauma and memory, ed. by Paul Antze \& Michael Lambek, 3-24. New York, NY: Routledge.

American Psychological Association (APA). 1980. Diagnostic and statistical manual of mental disorders, 3rd ed. Washington DC: American Psychiatric Publishing.

APA. 2013. Diagnostic and statistical manual of mental disorders, 5th ed. Washington DC: American Psychiatric Publishing.

Austin, J. L. 1962. How to do things with words. Oxford: Oxford University Press.

Bass, Ellen and Laura Davis. 1988. The courage to heal: A guide for women survivors of child sexual abuse. New York, NY: HarperCollins.

Blashfield, Roger K. 2012. The classification of psychopathology: Neo-Kraepelinian and quantitative approaches. New York, NY: Springer Science \& Business Media.

Bodkin, J. Alexander; Harrison G. Pope; Michael J. Detke; James I. Hudson. 2007. Is PTSD caused by traumatic stress? Journal of Anxiety Disorders 21.176-182. 
Breslau, Naomi; G. A. Chase; and J. C. Anthony. 2002. The uniqueness of the DSM definition of post-traumatic stress disorder: Implications for research. Psychological Medicine 32.573576.

Brewin, Chris R.; Ruth A. Lanius; Andrei Novac; Ulrich Schnyder; and Sandro Galea. 2009.

Reformulating PTSD for DSM-V: Life after criterion A. Journal of Traumatic Stress 22.366373.

Carroll, Noël. 2001. On the narrative connection. New perspectives on narrative perspectives, ed. by Willie van Peer and Seymour Benjamin Chatman, 21-42. New York, NY: State University of New York Press.

Compton, Wilson M. and Samual B. Guze. 1995. The neo-Kraepelinian revolution in psychiatric diagnosis. European Archives of Psychiatry and Clinical Neuroscience 245.196-201.

Crompton, Laura; Yael Lahav; and Zahava Solomon. 2017. Auditory hallucinations and PTSD in ex-POWs. Journal of Trauma \& Dissociation 18.663-678.

Day, Terri R. and Rycan C. W. Hall. 2016. PTSD and tort law. Comprehensive guide to posttraumatic stress disorders, ed. by Colin R. Martin; Victor R. Preedy; and Vinood B. Patel, 231-244. New York, NY: Springer.

Drescher, Kent D.; David W. Foy; Caroline Kelly; Anaa Leshner; Kerrie Schutz; and Brett Litz. 2011. An exploration of the viability and usefulness of the construct of moral injury in war veterans. Traumatology 17:8-13.

Eco, Umberto. 1976. A theory of semiotics. Bloomington, IN: Indiana University Press. Fisher, Janina. 2014. The treatment of structural dissociation in chronically traumatized patients. Trauma treatment in practice: Complex trauma and dissociation, ed. by Trine Anstorp and Kirsten Benum. Traumebehandling. Komplekse traumelidelser og dissosiasjon [Trauma treatment in practice: Complex trauma and dissociation.] Oslo: Universitetsforlaget.

Foucault, M. 1978. The History of Sexuality, Vols. 1, 2. New York, NY: Pantheon.

Gal, Susan. 2005. Language ideologies compared. Journal of Linguistic Anthropology 15.23-37. Goodwin, Charles and Alessandro Duranti. 1992. Rethinking context: An introduction.

Rethinking context: Language as an interactive phenomenon, ed. by Charles Goodwin and Alessandro Duranti, 1-42. Cambridge MA: Cambridge University Press. Hacking, Ian. 1991. The making and molding of child abuse. Critical Inquiry 17.253-288. 
Hacking, Ian. 1995. Rewriting the soul: Multiple personality and the sciences of memory. Princeton, NJ: Princeton University Press.

Hardy, Amy; David Fowler; Daniel Freeman; Ben Smith; Craig Steel; Jane Evans; Philippa Garety; Elizabeth Kuipers; Paul Bebbington; and Graham Dunn. 2005. Trauma and hallucinatory experience in psychosis. Journal of Nervous and Mental Disease 193.501-507.

Inoue, Miyako. 2004. What does language remember? Indexical inversion and the naturalized history of Japanese women. Journal of Linguistic Anthropology 14.38-56.

Irvine, Judith T. and Susan Gal. 2000. Language ideology and linguistic differentiation. Regimes of language: Ideologies, polities, and identities, ed. by Paul V. Kroskrity, 35-84. Santa Fe, CA: School of American Research Press.

Keane, Webb. 2003. Semiotics and the social analysis of material things. Language \& Communication 23.409-425.

Laibow, Rima E. and C. Shaffia Laue. 1993. Posttraumatic stress disorder in experienced anomalous trauma. International handbook of traumatic stress syndromes, ed. by John P. Wilson and Beverly Raphael, 93-103. Boston, MA: Springer.

Mayes, Rick and Allan V. Horwitz. 2005. DSM-III and the revolution in the classification of mental illness. Journal of the History of the Behavioral Sciences 41.249-267.

McCammon, Sarah. 2017. The warfare may be remote but the trauma is real. National Public Radio, 24 April 2017. Online: https://www.npr.org/2017/04/24/525413427/

McCarthy-Jones, Simon and Eleanor Longden. 2015. Auditory verbal hallucinations in schizophrenia and post-traumatic stress disorder: Common phenomenology, common cause, common interventions? Frontiers in Psychology 6.

McHugh, Paul R. and Glenn Treisman. 2007. PTSD: A problematic diagnostic category. Jouranl of Anxiety Disorders 21.11-222.

McNally, Richard J. 2003. Progress and controversy in the study of posttraumatic stress disorder. Annual Review of Psychology 54.229-252.

Miller, Laurence. 2015. PTSD and forensic psychology: Applications to civil and criminal law. New York, NY: Springer.

Morrison, Anthony P.; Lucy Frame; and Warren Larkin. 2003. Relationships between trauma and psychosis: A review and integration. British Journal of Clinical Psychology 42.331-353. 
Ostwald., Peter F. 1964. How the patient communicates about disease with the doctor. Approaches to semiotics, ed. by Thomas A. Sebeok; Alfred S. Hayes; and Mary Catherine Bateson, 11-34. The Hauge: Mouton \& Co.

Peirce, Charles S. 1931-1958. Collected papers of Charles S. Peirce, vol. 2, ed. by Charles Hartshorne and Paul Weiss. Cambridge, MA: Harvard University Press.

Peirce, Charles S. 1940[1897, 1903, 1910]. Logic as semiotic: The theory of signs. Philosophical writings of Peirce, ed. by Justus Buchler, 98-119. New York, NY: Dover.

Press, Eyal. 2018. The wounds of the drone warrior. New York Times, 13 June 2018. Online: https://www.nytimes.com/2018/06/13/magazine/veterans-ptsd-drone-warrior-wounds.html

Ray, Christopher L. 2014. Feigning screeners in VA PTSD compensation and pension examinations. Psychological Injury and Law 7.370-387.

Resick, Patricia A.; Michelle Bovin; Amber Calloway; Alexandra Dick; Matthew King; Karen Mitchell; Michael Suvak; Stephanie Wells; Shannon Wiltsey Stirman; and Erika Wolf. 2012. A critical evaluation of the complex PTSD literature: Implications for DSM-5. Journal of Traumatic Stress 25.241-251.

Şar, Vedat. 2011. Developmental trauma, complex PTSD, and the current proposal of DSM-5. European Journal of Psychotraumatology 2.1-9.

Scott, Wilbur J. 1990. PTSD in DSM-III: A case in the politics of diagnosis and disease. Social Problems 37.294-310.

Sebeok, Thomas A. 1994. Signs: An introduction to semiotics. London, UK: University of London Press.

Shapiro, Francine. 2001. Eye Movement Desensitization and Reprocessing (EMDR), 2nd ed. New York, NY: The Guilford Press.

Silverstein, Michael. 1976. Shifters, linguistic categories, and cultural description. Meaning in anthropology, ed. by Keith H. Basso and Henry A. Selby, 11-55. Albuquerque, NM: University of New Mexico Press.

Silverstein, Silverstein. 2003. Indexical order and the dialectics of sociolinguistic life. Language \& Communication 23.193-229.

Van Der Hart, Onno; Ellert R. S. Nijenhuis; and Kathy Steele. 2006. The haunted self: Structural dissociation and the treatment of chronic traumatization. New York, NY: W. W. Norton \& Company. 
Van Der Kolk, Bessel. 2013. The body keeps the score: Brain, mind, and body in the healing of trauma. New York, NY: Penguin Books.

Wilson, Mitchell. 1993. DSM-III and the transformation of American psychiatry: A history. The American Journal of Psychiatry 150.399-410.

Young, Allan. 1995. The harmony of illusions: Inventing post-traumatic stress disorder. Princeton, NJ: Princeton University Press. 